\title{
Sarcoidosis case diagnosed by laparoscopic splenectomy
}

Hüseyin Çiyiltepe ${ }^{1}$, Durmuş Ali Çetin ${ }^{1}$, Ulaş Aday ${ }^{1}$, Ebubekir Gündeş ${ }^{1}$, Emre Bozdağ ${ }^{1}$, Fulya Çiyiltepe ${ }^{2}$

${ }^{1}$ Department of Gastroenterological Surgery, Kartal Kosuyolu High Speciality Education and Training Hospital, Istanbul, Turkey

2Intensive Care Unit, Haydarpaşa Numune Education and Training Hospital, Istanbul, Turkey

Submitted: 6 January 2017

Accepted: 4 February 2017

Arch Med Sci Civil Dis 2017; 2: e35-e36

DOI: https://doi.org/10.5114/amscd.2017.66477

Copyright @ 2017 Termedia \& Banach

Sarcoidosis is a chronic, multisystemic inflammatory disease of unknown etiology characterized by the presence of non-necrotizing granulomatous lesions. It is most commonly observed between the ages of 20 and 50. The most commonly involved organ is the lungs. Pulmonary involvement is observed in more than $90 \%$ of the patients and extrapulmonary involvement is also frequently observed. According to frequency, lymph nodes, eyes, skin, liver and spleen may be involved. Splenic involvement is reported in up to $40 \%$ of these patients [1].

Patients are usually diagnosed by biopsies of tissues or organs involved, along with clinical and radiological findings. Most cases are asymptomatic. There may be nonspecific symptoms or symptoms specific to the involved organ may be present. The most common symptoms of splenic involvement include splenomegaly, abdominal swelling and complaints of epigastric pain [2]

The purpose of this study is to emphasize that sarcoidosis can rarely be diagnosed with extrapulmonary involvement and associated symptoms, although the diagnosis of sarcoidosis is typically established through clinical and radiological findings associated with pulmonary involvement.

The 51-year-old female patient presented to our outpatient clinic with complaints of fever, fatigue, weight loss, and blunt abdominal pain on the upper left that she had been experiencing for a month. Abdominal examination showed epigastric tenderness, and the trachea area was closed. Other system examinations were normal. Laboratory tests showed white blood cells: $7800 / \mathrm{mm}^{3}$, hemoglobin: $10.8 \mathrm{~g} / \mathrm{dl}$, hematocrit: $31.2 \%$, platelets: $306000 / \mathrm{mm}^{3}$, erythrocyte sedimentation rate: $32 \mathrm{~mm} / \mathrm{h}$. The chest X-ray was normal. In abdominal ultrasonography (USG), the spleen was measured to be $136 \mathrm{~mm}$ in size and multiple nodules were observed inside the parenchyma. The patient was scanned with dynamic upper abdominal computed tomography (CT). Along with moderate growth of the spleen, multiple hypodense lesions were observed in the parenchy$\mathrm{ma}$, the largest being $1 \mathrm{~cm}$ (Figure 1). Lymph nodes were seen at the hilum of the spleen. In terms of differential diagnosis, fine needle biopsy was suggested to the patient, but as she refused because of the possible complications that may develop, laparoscopic splenectomy was planned and successfully performed (Figure 2). In the microscopic examination, non-carcinomatous granulomatous inflammations were observed and morphological findings were compatible with sarcoidosis.

Consultations with the chest disease department were done for the patient in order to evaluate lung involvement. In thorax CT, hilar lymph-

\author{
Corresponding author: \\ Hüseyin Çiyiltepe \\ Department of \\ Gastroenterological Surgery \\ Kartal Kosuyolu \\ High Speciality \\ Education and \\ Training Hospital \\ 34000 Istanbul, Turkey \\ E-mail: drciyiltepe@hotmail. \\ com
}




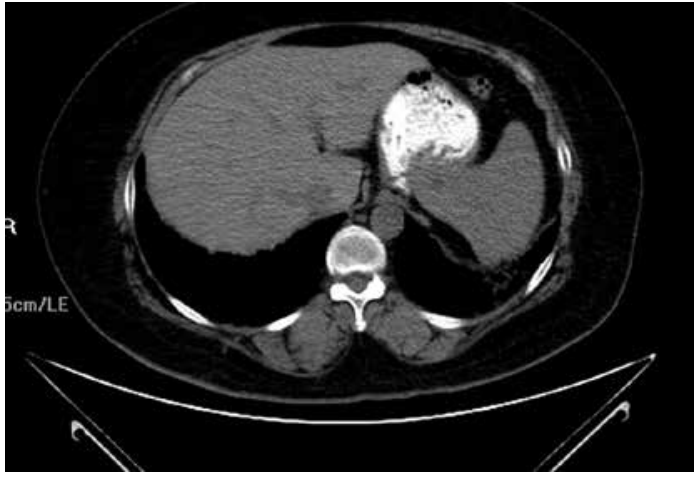

Figure 1. Abdominal CT image

adenopathies and infiltrative involvements were observed in both lungs. The patient, with no respiratory symptoms and whose breathing function tests were normal, was followed up as radiographic stage 2 sarcoidosis.

The etiology of sarcoidosis is a granulomatous disease which has remained completely unexplained. The clinical presentation and course of sarcoidosis are rather variable. Almost all the organs in the body can be involved. Pulmonary involvement is present in more than $90 \%$ of cases [3]. Two-thirds of the patients are asymptomatic and are usually diagnosed with bilateral hilar lymphadenopathies identified by chest X-ray performed during routine examinations. Clinical symptoms depend on the duration of the disease, the involved organ, the prevalence of the disease and the activity of the granulomatous event. Symptoms often affect the respiratory system, and in most cases, dyspnea, cough and chest pain are seen. Additionally, systemic symptoms such as fever, fatigue and weight loss can be widely observed [4].

Splenomegaly in sarcoidosis is observed in $10-20 \%$ of patients, often with hepatomegaly and rarely with hypercalcemia. In autopsy series and celiac angiography and splenic biopsies performed on patients, granulomas in the spleen are observed in $50-70 \%$ of cases. In sarcoidosis, the spleen grows without any clinical signs, but anemia, leukopenia, and thrombocytopenia begin to be seen after exceeding the costal margin of $4 \mathrm{~cm}$. Sometimes massive splenomegaly might occur; rarely splenic rupture has been reported [5].

For the diagnosis of sarcoidosis, non-rotatable granulomatous reaction must be found in tissue biopsy apart from clinical, laboratory and radiological findings. Biopsy specimens should be taken with the invasive method from the organ most easily accessible. In many centers, the probability of high diagnosis with skin and transbronchial lung biopsy has replaced the biopsy of the mediastinal lymph node and liver due to high specificity and low morbidity rates [6].

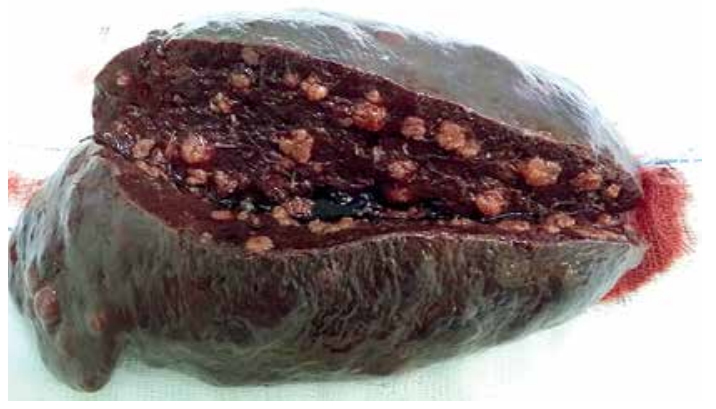

Figure 2. Splenectomy material

In this case, it has been shown by abdominal tomography that the spleen was involved with homogeneous nodular lesions. Lymphoma, metastatic involvement or infectious diseases such as tuberculosis and histoplasmosis are very important in differential diagnosis, especially when the involvement of the spleen in sarcoidosis is of nodular form. Precise distinction of sarcoidosis from such diseases can only be established by histopathological sampling. With corticosteroid treatment, spleen sizes usually return to normal, but there is an indication for splenectomy in cases that are nonresponsive to treatment [7]. In our case, we performed laparoscopic splenectomy since the patient did not accept histopathological sampling.

The differential diagnosis of sarcoidosis should be kept in mind in patients who present with abdominal pain and multiple masses in the spleen and who do not have clinical symptoms of other systems, as was the case with our patient.

\section{Conflict of interest}

The authors declare no conflict of interest.

\section{References}

1. Valeyre D, Nunes H, Duperron F, Soler P, Kambouchner M, Brauner M. Sarcoïdose. EMC Pneumologie 2005; 2: 147-64.

2. Warshauer DM, Lee JK. Imaging manifestations of abdominal sarcoidosis. Am J Roentgenol 2004; 182: 15-28.

3. Kalemci S, Ekrem K. Noduler spleen involvement of sarcoidosis. Med J Kocatepe 2011; 12: 32-5.

4. Iannuzzi MC, Rybicki BA, Teirstein AS. Sarcoidosis. N Engl J Med 2007; 357: 2153-65.

5. Salazar A, Mañá J, Corbella X, Albareda JM, Pujol R. Splenomegaly in sarcoidosis: a report of 16 cases. Sarcoidosis 1995; 12: 131-4.

6. Bircan A, Kılıç Ö, Gökırmak M, Öztürk Ö, Akkaya A. A rare involvement of sarcoidosis: massive splenomegaly. Turk Thorac J 2011; 12: 84-7.

7. Mihailovic-Vucinic V, Om PS. Atlas of Sarcoidosis: Pathogenesis, Diagnosis and Clinical Features. Springer 2005; 65-7. 